London, UK

kathyoxtoby1@gmail.com

Cite this as: BMJ 2021;372:n739

http://dx.doi.org/10.1136/bmj.n739

Published: 24 March 2021

WORKFORCE SAFETY

\title{
Another epidemic: abuse and violence towards doctors from patients and the public
}

\begin{abstract}
In the context of covid-19, persistent abuse of NHS doctors compounds the emotional toll on staff, damages morale, and threatens patient safety. Plans to stem the tide may be insufficient, as Kathy Oxtoby reports
\end{abstract}

\section{Kathy Oxtoby journalist}

"In just a few weeks patients physically assaulted three of my colleagues in the emergency department," Susan Robinson, a consultant in emergency medicine based in Cambridge, tells The BMJ. "I've experienced and noticed more verbal abuse, often from relatives who are distressed because they are not allowed to stay with patients, or from patients frustrated by long waits."

Nearly $15 \%$ of respondents to the latest NHS Staff Survey, covering 2020, reported experiencing at least one episode of violence from patients, their relatives, or other members of the public, similar to $2019 .{ }^{1}$ And over a third of staff who had frequent face-to-face contact with service users reported experiencing at least one incident of bullying, harassment, or abuse from patients, relatives, or the public in the past year.

As the covid-19 pandemic places unprecedented pressures on healthcare services and staff, anecdotes have brought the problem of abuse to the fore. "One doctor told us they had experienced more unpleasantness in six months than in all their previous 50 years working in healthcare," says Pallavi Bradshaw, medicolegal lead for risk prevention at the Medical Protection Society (MPS), which protects and supports the professional interests of healthcare staff.

Of 1251 doctors who responded to an MPS survey last September and October, 375 (30\%) had been verbally abused by patients or relatives while at work during the pandemic. Another 63 (5\%) had experienced physical abuse. ${ }^{2}$ And $88(7 \%)$ had experienced abuse outside the workplace, such as when using an NHS queue at a supermarket.

Samantha Batt-Rawden, president of the grassroots campaigning organisation the Doctors' Association UK (DAUK), told The BMJ that doctors continued to receive abuse despite "risking their lives since March 2020.” In a recent survey, DAUK's members reported verbal and physical abuse including insults, racism, death threats, and violence. One respondent told the campaign, "Physical abuse is a regular part of being an emergency medicine doctor. I have been hit and bruised by many patients for a variety of reasons. All staff have a story to tell, and it's rare that the patients ever have to face any consequences."

The problem is not confined to secondary care. Bradshaw says, “There's a perception that GPs aren't offering enough face-to-face appointments, despite face-to-face appointments increasing in recent months, and this has resulted in complaints, frustration, and abusive behaviour." One practice in Bristol was painted with offensive graffiti. ${ }^{3}$

She explains, "For hospital doctors the reasons are different; for example, patients have been unable to see their sick relatives during a particularly stressful time. The increasingly long waiting times for specialty referrals have also led to a huge amount of patient dissatisfaction.”

It's hard to know the true extent of the problem, however: much abuse goes unreported, ${ }^{4}$ and national annual data on physical assaults against NHS staff are no longer published. Almost half of NHS staff surveyed had not reported an incident of harassment, bullying, or abuse in the past year. ${ }^{1}$ Batt-Rawden told The BMJ that three quarters (111) of 150 respondents to the DAUK survey had experienced abuse but not reported it.

One common misperception is that violence from patients is to be expected and is just another part of the job. ${ }^{5}$ Doctors may "try to rationalise and excuse, to a degree, patients' angst,” says Ellie Mein, medicolegal adviser for the Medical Defence Union. They may attribute a patient's violent or aggressive behaviour to physical or mental health problems and decide not to report it.

Stress, anxiety, and dependence on drugs or alcohol are often factors when patients and relatives are abusive, says Ian Higginson, vice president of the Royal College of Emergency Medicine. "The patient may have had a psychotic episode, have a behavioural personality disorder, or dementia," he tells The BMJ. Sometimes "it's difficult to draw a line between what is deliberate abusive behaviour and what is the result of illness."

\section{Impact of abuse}

When a patient punched, kicked, spat at, and racially abused Sukhpreet Singh Dubb in the emergency department in 2014 he was left shaken, as he wrote in The BMJ soon after. "This was not what I signed up for," says Dubb, now a level 4 specialty trainee at Norfolk and Norwich Hospital's oral and maxillofacial surgery department. "You question your duty of care. You become worried that in trying to help a person you could be attacked." 
For most doctors, says Bradshaw, "covid-19 will be the biggest health crisis in their careers, with countless patients and colleagues lost." Without support to tackle concerns about mental wellbeing, including those caused by verbal and physical abuse, she warns that "doctors are at risk of becoming disillusioned or will suffer in silence with psychological injuries, both of which put the safety of themselves and their patients at risk." In the MPS survey, two in five doctors (525) reported worse mental wellbeing than before the pandemic.

As well as the emotional toll on individuals, abuse can damage the morale of the entire workforce, and patient safety may suffer. "It makes doctors stressed and affects our performance, even to the extent of not being able to give the right diagnosis and treatment," says Chris Turner, a consultant in emergency medicine based in the West Midlands and cofounder of Civility Saves Lives, an organisation promoting civility in medicine.

Prevalent abuse also affects doctors' families. Dubb has noted "a subtle shift, from your family wondering if the shift will be busy or if you'll finish on time, to 'Will you return home safely?' Some colleagues have left the profession because of abuse from patients. But my enthusiasm for being a doctor has continued."

He adds, "Often, verbal and physical abuse stem from anger, frustration, anxiety, and pain.” Greater public understanding of the challenges doctors and nurses face-such as staff shortages-could help, he says.

\section{Employers must protect staff}

"It is not enough simply to clap once a week for NHS staff," as the public were doing in the first lockdown of 2020, says Batt-Rawden, DAUK president. "We have to create a protected workplace that doesn't leave them at risk of abuse."

Martin Marshall, chair of the Royal College of General Practitioners, says that any abuse of staff is "simply unacceptable." General practices can remove abusive patients from their list without warning if the police have been involved, he told The BMJ.

Hospitals security in general is currently "inadequate," says Higginson, the emergency medicine doctor. "Security teams are under-resourced, and how much hospitals invest in security will depend on how seriously it is taken by the trust." And the football-style "yellow" and "red" warnings used by trusts don't work well, he adds, "because it's very difficult to turn patients away."

Since April 2020, NHS services in England have been able to bar non-emergency patients or visitors who behave in a discriminatory or harassing way towards staff. ${ }^{7}$ Previously, organisations could refuse services only if patients were aggressive or violent. Since September the maximum sentence for assaulting emergency workers such as doctors in England and Wales has doubled to two years.

However, "simply increasing sentences is not the answer," says Higginson, who wants to see it become "culturally and judicially unacceptable to be abusive or violent towards healthcare professionals, with consequences that are enacted, meaningful, and supported by the public.”

The government introduced an NHS violence reduction strategy in 2018, aiming "to help victims give evidence and get prosecutions." Building on this strategy, in December NHS England and NHS Improvement published a national Violence Prevention and Reduction Standard for NHS organisations to encourage "a safe and secure working environment for NHS staff, safeguarding them against abuse, aggression and violence." ${ }^{\text {D }}$ Developed with the Social
Partnership Forum - which includes NHS Employers, trade unions, and the Department of Health and Social Care-the standard requires organisations to assess and manage risks, implement change, involve staff and other stakeholders, and provide resources and training.

\section{Work in progress}

The NHS People Plan, due to be implemented this year, emphasises reducing violence and includes $€ 1.1 \mathrm{~m}(€ 1.3 \mathrm{~m} ; \$ 1.5 \mathrm{~m})$ of funding to pilot body worn cameras in four ambulance trusts and for training. ${ }^{10}$ However, doctors say that more needs to happen on a local and national level.

The MPS's Bradshaw sees "credible initiatives" in the plan, such as every NHS organisation having a "wellbeing guardian," but she worries about a lack of commitment to what are presented as suggestions and of central government funding. "They do not deal with the effects of verbal and physical abuse on the mental wellbeing of healthcare professionals," she says.

David Wrigley, deputy chair of council at the BMA, says, "The BMA supports the violence reduction strategy; however, its success will depend on how it is implemented by employers. The BMA has been clear that more support is needed to reduce incidences of violence toward doctors."

For GPs, says Wrigley, clinical commissioning groups should introduce consistent, systemwide approaches to deal with abusive behaviour. He wants NHS England and NHS Improvement to provide occupational health services for all staff so that victims get the help they need.

Robinson, the emergency medicine consultant, notes how times have changed. She says, "Two decades ago, the culture was that you just got on with it: there were no reporting systems or security. Today, there are clear policies that abuse won't be tolerated, and we're encouraged to formally report incidents, though not everybody does. We have training in how to de-escalate incidents and personal panic buttons to call security."

But this is not enough, she adds, particularly as patients' and relatives' frustrations due to covid-19 boil over. She concludes, "This is now so toxic an environment that doctors will leave emergency medicine. We need local and national campaigns to help patients understand that abuse affects our ability to think clearly and can impinge on patient safety as well as staff wellbeing."

\section{What to do if you are abused ${ }^{11}$}

- Doctors should "always report incidences to their line manager and inform the police of any situations involving physical attack or serious cases of threatening verbal abuse or intimidation," says David Wrigley, deputy chair of council at the BMA.

- "Talk about what happened with family, friends, and colleagues so that you can heal," says Sukhpreet Singh Dubb, emergency medicine doctor. "Don't try to 'normalise' the abuse, as I did at first. Abuse isn't just "a bad day."”

- Follow your practice's or trust's security procedures and take time out after receiving abuse, advises Zainab Najim, a trainee GP based in Norfolk and co-secretary of the grassroots campaign the Doctors' Association UK. She recommends training on managing conflict with patients but acknowledges that there is no standard approach. 
Kate Simpson, senior GP partner, Halifax: "Verbal abuse is emotionally damaging"

"We're seeing fewer patients face to face now, so most abuse is over the phone-shouting, swearing, personal attacks. It sticks in the mind. Accusations that you're not doing your job properly are even more emotionally damaging when you're trying to help people.

"GPs have had a lot of negative media coverage, and this makes people less respectful. We use a 'buddy' system, so if someone has had an abusive call they can talk to a senior manager. The patient will be told that abusing staff is not acceptable.

"Self defence training should be funded. GPs feel demoralised, and doctors nearing retirement age are saying that the job just isn't worth it any more."

\section{Matt Morgan, intensive care consultant, Cardiff: "Online abuse is abuse"}

“I wrote on social media that medicine can't save everybody, and sometimes ventilation or resuscitation isn't in a critically ill patient's best interests. National media coverage led to many comments, including unpleasant ones, such as "You don't care about old people," and "You fascist piece of shit." Some suggested that doctors were exploiting our position. The insults didn't bother me, but the untruths did.

"Hate messages are abuse: you should talk to other people about online abuse rather than keep it to yourself. It's one thing being abused at work but another being abused while at home sitting on the sofa.

"I now mute people if their comments are unkind, and I report anybody who is threatening or abusive. I also avoid social media after a long, busy day."

Competing interests: I have read and understood BMJ policy on declaration of interests and have no relevant interests to declare.

Provenance and peer review: Commissioned; not externally peer reviewed.

1 NHS Survey Coordination Centre. NHS staff survey 2020: national results briefing. Mar 2021. https://www.nhsstaffsurveys.com/Caches/Files/ST20\%20national\%20briefing\%20doc.pdf.

2 Medical Protection. 1 in 3 doctors have suffered verbal or physical abuse during covid-19. 18 Nov 2020. https://www.medicalprotection.org/uk/articles/1-in-3-doctors-have-suffered-verbal-orphysical-abuse-during-covid-19.

3 Bostock N. Abusive graffiti daubed on side of GP practice in Bristol. GP2020 Oct 26. https://www.gponline.com/abusive-graffiti-daubed-side-gp-practice-bristol/article/1698324.

4 Violence against NHS staff: read the full report. Health Serv 2018 Apr 17. https://www.hsj.co.uk/workforce/violence-against-nhs-staff-read-the-full-report/7022168.article.

5 Jenkins MG, Rocke LG, MCNicholl BP, Hughes DM. Violence and verbal abuse against staff in accident and emergency departments: a survey of consultants in the UK and the Republic of Ireland. J Accid Emerg Med 1998;15:262-5. doi: 10.1136/emj.15.4.262 pmid: 9681312

6 Dubb SS. It doesn't "come with the job": violence against doctors at work must stop. BMJ 2015;350:h2780. doi: 10.1136/bmj.h2780 pmid: 26013379

7 Rimmer A. NHS trusts are given new powers to bar racist patients. BMJ 2020;368:m644. doi: 10.1136/bmj.m644 pmid: 32071033

8 Department of Health and Social Care. NHS violence reduction strategy: stronger protection from violence for NHS staff. 31 Oct 2018. https://www.gov.uk/government/news/stronger-protectionfrom-violence-for-nhs-staff.

9 NHS, Social Partnership Forum. Violence prevention and reduction standard. Dec 2020. https://www.england.nhs.uk/wp-content/uploads/2020/12/B0319-Violence-Prevention-ReductionStandards.pdf.

10 NHS. NHS people plan. Updated 6 Aug 2020. https://www.england.nhs.uk/ournhspeople/onlineversion/.

11 Devlin M. Dealing with threats and violence in the healthcare setting. MDU J 2019. https://mdujournal.themdu.com/issue-archive/spring-2019/dealing-with-threats-and-violence-in-the-healthcare-setting. 